1989 the American Brady plan encouraged the swapping of debt for equity, and in 1990 John Major (then chancellor of the exchequer) produced the Trinidad plan, which has led to some rich countries writing off debts of the poorest countries. But the debt crisis is far from resolved and will hang over the Rio summit. The Economist has suggested that mandating commercial banks to write off the debts might actually appeal to the banks because they know that they will never get much of the money back and their main anxiety is that they will suffer competitively if they unilaterally write off debts. ${ }^{12}$

Third World debt and poverty must matter to those in rich countries-not only because having almost two billion without enough to eat and clean water to drink is wrong but also because poverty is tied up so closely with destruction of the environment. As the World Bank explained last week, poverty leads to population growth, air pollution, desertification, and soil degradation." "The state of their economies," said the Financial Times, "gives the people [in poor countries] no choice but to destroy their natural endowments to survive."'13 The World Bank argues that economic development should lead to less pollution, but the effect on carbon dioxide emissions of a doubling of per capita coal consumption in China by 2000 (and greater increases are planned) would more than offset the United States ceasing to use coal at all. ${ }^{14}$ The earth summit cannot ignore poverty.

But what does all this mean to doctors? Poverty and the state of the environment together probably have more effect on health than anything else, but doctors may feel overwhelmed by the scale of the problem-most politicians are. But many doctors similarly felt overwhelmed by the threat of nuclear destruction; yet doctors played a central role in reducing the threat of nuclear war. We can do the same for world poverty and environmental destruction-through education of ourselves and others, research, campaigning, and individual and concerted action.

Editor, $B M \mathcal{F}$

RICHARD SMITH

Consultant Physician,

ROBIN STOTT

Lewisham Hospital,

London SE13 6LH

1 World Bank. Development and the environment. Washington: World Bank, 1992

2 Godlee F. Rio agrees to costly compromise. BMJ 1992;304:1329-30.

3 Gillen D. Decade of the disaster. BMF 1991;303:1017.

4 Christian Aid. Banking on the poor. London: Christian Aid, 1991.

5 George S. The debt boomerang: how Third World debt harms us all. London: Pluto Press, 1992.

6 Unicef. State of the world's children. Oxford: Oxford University Press, 1991.

7 Leger Sivard R. World military and social expenditures. Wrathingtess, 1991.

8 Distracted by debt: the developing countries' debt troubles have made the 1980 s the lost decade. Economist 1989 Sept 23.

Kanii N, Kanji N, Manji F. From development to sustained crisis-structural adjustment, equity, and health. Soc Sci Med 1991;33:985-93.

Clark J, Allison C. Zambia - debt and poverty. Oxford: Oxfam, 1989.

10 Clark J, Allison C. Zambia-debt and poverty. Oxford:

11 Unesco. Statistical yearbook. Paris: Unesco, 1989.

Survey of the IMF and the World Bank. And forgive us our debts-the lessons of the debt debacle are still being learned. Economist 1991 Oct 12

13 Development and the environment. Financial Times 1992 May 18:16.

14 Ehrlich PR, Ehrlich AH. The population explosion. New York: Simon and Schuster, 1990

\title{
After Windscale (Sellafield)
}

\section{Studies have increased our understanding of cluster analysis but not why clusters of childhood leukaemia occur}

The past decade has seen increasing concern in Britain about the possibility that exposure to a raised level of environmental radiation could lead to an increased risk of childhood leukaemia. This concern was initially fuelled by a well researched television programme testifying to the possibilities of clusters of cases of childhood leukaemia around British nuclear installations and followed by a plethora of reports from different parts of the country based on different statistical methods and geographical groups. Most suggested a possible increase in risk around installations, but overall the results were not clear cut and led to considerable confusion.

A recent publication on the geographical epidemiology of childhood leukaemia and non-Hodgkin's lymphomas in Great Britain, edited by Gerald Draper, ${ }^{1}$ is remarkable in that it has assembled contributions from nearly all the current major researchers in this country, with useful summaries and overview papers pulling together the results and discussing reasons for inconsistencies.

The results are based on 9411 patients born in Britain whose cancers were registered during 1969-83. The data are strengthened by the high quality and completeness of the registration of these childhood cancers, certainly for the more recent years.

Although the main findings amount to far less than a break through, they give us some clear and consistent leads for further research.

As in other Western countries, the lymphocytic and unspecified leukaemias had an annual incidence of 30 per million children aged under 15 and the pronounced and unexplained peak at the age of 2-3 years was confirmed. In contrast, the lymphomas have an overall incidence of 6 per million children, are rare before the age of 2 , and have a fairly constant rate thereafter. The existence of a geographical variation in incidence was confirmed, as was a small trend towards an increase with increasing socioeconomic status (better off children are more likely to get leukaemia).

Whether clusters exist ${ }^{2}$ (which raises the possibility of environmental causes) has been investigated with several independent statistical techniques. The conclusions are that geographical clusters of the leukaemias do occur, particularly among those aged $0-4$. There was some evidence that the early childhood peak was most pronounced in sparsely populated areas. Reference was made to the papers by Kinlen and colleagues,${ }^{34}$ which suggested that for young children recent population turnover predisposes to new exposure to viral diseases and that these, perhaps interacting with another hazardous exposure, may initiate the malignant process.

The presence of raised incidence near nuclear installations and other potentially polluting sources was confirmed, but several other districts with previously unrecognised high incidences were also found.

Some of the most important aspects of the report are its expqsition of problems relating to the reliability of estimates of the population in small areas, particularly between censuses and in places where there is considerable movement of the population. A need clearly exists to improve and make more contemporary local population estimates, as well as to continue to develop methods of investigating clusters which are independent of such data.

In addition stress is laid on the importance, in childhood leukaemias, of basing demographic and other investigations on the characteristics of the place of residence where the 
disease onset is most likely to have occurred. Longstanding evidence that fetal exposure to medical radiation is a risk factor, ${ }^{5}$ together with the report by Gardner and his colleagues $^{6}$ linking risk to paternal occupational exposure to radiation immediately before conception, suggest that residence at birth (or before birth) may be more relevant than residence at the time of registration or death. A recent study of the cases arising in children living around Dounreay, ${ }^{7}$ however, found that the risk was no higher in the children born in the area than in those moving there after birth.

Has the large amount of research money that has gone into the epidemiology of this small but unquestionably important problem been justified? Certainly it has stimulated the development of new statistical approaches to spatial analyses, which may be applicable to other circumstances. It has also strengthened the validity of what was previously weak evidence on the presence of clusters of cases, even if we have learnt little more about the effects of environmental radiation. Considerably more research is needed, probably on an individual basis, before the causes of these devastating diseases are fully understood.

Professor Emeritus

EVA ALBERMAN

Department of Preventive and

Environmental Medicine,

Wolfson Institute of Preventive Medicine,

Medical College of St Bartholomew's Hospital,

London ECIM 6BQ

1 Office of Population Censuses and Surveys. The geographical epidemiology of childhood leukaemia and non-Hodgkin lymphomas in Great Britain, 1966-83. London, HMSO, 1991. (Studies in medical and population subjects No 53 .)

2 Knox G. Epidemiology of childhood leukaemia in Northumberland and Durham. Br f Prev Soc Med 1964;18:17-24

Kinlen L. Evidence for an infective cause of childhood leukaemia: comparison of a Scottish new town with nuclear processing sites in Britain. Lancet 1988;ii:1323-7.

Kinlen LJ, Clarke K, Hudson C. Evidence from population mixing in British new towns 1946-85 of an infective basis for childhood leukaemia. Lancet 1990; 336:577-82.

Stewart A, Webb J. Hewitt DA. A survey of childhood malignancies. BMF 1958;i:1445-508.

6 Gardner MJ Snee MP, Hall A, Powell CA, Downes S, Terrell JD Results of a case-control study of leukaemia and lymphoma among young people near the Sellafield nuclear plant in West Cumbria. leukaemia and lymphom

7 Black RJ, Urquhart JD, Kendrick SW, Bunch KJ, Warner J. Incidence of leukaemia and other cancers in birth and school cohorts in the Dounreay area. BMF 1992, in press.

\section{Alcohol and cardiac arrhythmias}

\section{Patients with unexplained tachyarrythmias should be questioned about their drinking}

Heavy drinking increases the risk of cardiac arrhythmias whether or not heart disease is present..$^{1-8}$ The evidence has come from clinical observations, ${ }^{12}$ retrospective case-control studies, ${ }^{3}$ controlled studies of consecutive admissions for supraventricular tachyarrhythmias, ${ }^{45}$ and prospective epi-

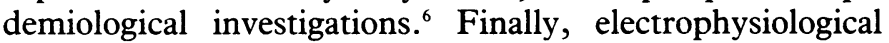
studies have shown that alcohol can facilitate the induction of tachyarrhythmias in heavy drinkers with a history of alcohol related heart irregularities. ${ }^{78}$

The potential of alcohol misuse to induce arrhythmias is best established in atrial fibrillation. Patients (especially men) admitted for idiopathic atrial fibrillation have been shown to have consumed more alcohol during the week preceding their admission than either control patients ${ }^{4}$ or the population outside hospital. ${ }^{5}$ In one study $60 \%$ of patients with idiopathic atrial fibrillation coming on at the weekend were problem drinkers, according to the CAGE questionnaire, ${ }^{9}$ compared with only $12 \%$ in the community. ${ }^{10}$ The association of alcohol with other types of supraventricular tachyarrhythmias is less clear, " but in the Kaiser Permanente study people consuming more than six drinks a day had a higher risk of all supraventricular tachyarrhythmias than people matched for age, sex, race, and smoking but consuming less than one drink a day. ${ }^{6}$ Finally, alcohol has occasionally also been shown to promote the onset of ventricular tachyarrhythmias. ${ }^{18}$

How might alcohol promote arrhythmias? Subclinical alcoholic disease of the heart muscle may contribute by producing patchy delays in conduction, and potassium and magnesium depletion may also be factors, ${ }^{1}$ as may the hyperadrenergic state accompanying alcohol withdrawal. When prolonged alcohol misuse is halted the adrenaline and noradrenaline concentrations in the blood are raised and the density of $\beta$ adrenoceptors in lymphocytes, which had been reduced, rapidly returns to normal. ${ }^{12}$ Studies in animals have shown similar reversal and even an overshoot of the number of $\beta$ adrenoceptors in the heart after withdrawal of alcohol. ${ }^{13}$ And alcohol has an acute electrophysiological action which is also likely to be important: in some heavy drinkers arrhythmias are induced easily after two to three whiskies but not in the sober state. ${ }^{78}$

Alcoholics commonly die suddenly and unexpectedly, but the cause of death often remains unexplained even at necropsy. ${ }^{14}$ There may be more than one fatal path of events, but primary ventricular arrhythmia culminating in fibrillation ranks high among the possibilities. In one study of victims of sudden death $26 \%$ of men under 50 had a history of heavy drinking and myocardial changes compatible with chronic alcoholic injury. ${ }^{15}$ Decreased variability of heart rate-a sign of cardiac vagal neuropathy and a factor notorious for increasing the risk of death after myocardial infarction - is a relatively common finding among men dependent on alcohol. ${ }^{16}$ By contrast, however, regular modest drinking seems to be associated with a reduced risk of primary cardiac arrest in people without prior cardiovascular disease. ${ }^{17}$

There are no good data on the management of alcohol related cardiac arrhythmias. In our experience most episodes terminate within 24-48 hours either spontaneously or after treatment with $\beta$ blockers combined with adequate sedation, rehydration, and treatment of any potassium and magnesium depletion. Treatment of the underlying alcohol misuse must not be neglected. In an attempt to help identify covert alcoholism we recommend the administration of the CAGE questions to all patients presenting with otherwise unexplained acute tachyarrhythmias. ${ }^{9}$ Studies in people who were not alcoholics have shown that a moderate intake produces varied and partly conflicting changes in impulse conduction and in the number of premature beats. The effects of social drinking on the frequency, severity, and inducibility of clinically important arrhythmias have not been properly studied. Advice to patients who are not alcoholics should therefore be based on clinical judgment and on the understanding that arrhythmogenic effects of alcohol seen in heavy drinkers may not hold for social alcohol consumption.

PEKKA KOSKINEN Registrar in Medicine MARKKU KUPARI

Division of Cardiology,

Consultant in Cardiology

First Department of Medicine,

Helsinki University Central Hospital, 00290 Helsinki, Finland 